\title{
Unlocking Access To Novel Medicines In China-A Review From A Health System Perspective
}

This article was published in the following Dove Press journal:

Risk Management and Healthcare Policy

\author{
Yifan Diao (D) ${ }^{\prime}$ \\ Mingshuang $\mathrm{Li}^{\prime}$ \\ Zhiran Huang' \\ Jing Sun (iD) \\ Yoke Ling Chee ${ }^{2}$ \\ Yunali Liu'
}

'School of Public Health, Chinese Academy of Medical Sciences \& Peking Union Medical College, Beijing 100730 ,

People's Republic of China; ${ }^{2}$ Third World Network, George Town 10400, Penang, Malaysia
Correspondence: Jing Sun; Yunali Liu School of Public Health, Chinese

Academy of Medical Sciences \& Peking Union Medical College, 5

Dongdansantiao, Dongcheng District, Beijing 100730, People's Republic of China $\mathrm{Tel} / \mathrm{Fax}+86-10-65105537$

Email sunjing@sph.pumc.edu.cn; yliu@pumc.edu.cn

\begin{abstract}
China's healthcare reform aims to provide affordable and equitable basic healthcare for all by 2020. Access to medicines is an essential part of the healthcare. The efforts of promoting access to medicines have been moving from meeting the needs of the basic healthcare, towards increasingly dedicated resources to offer breakthrough therapies. Looking at access to novel medicines from a health system perspective, and placing the changes China has made into that system context, this paper makes a comprehensive review of the progress of access to novel medicines in China. The review drew on two sources of information, which included desk review of published and grey literature, and key informant interview. Five hurdles were identified which create barriers of access to novel medicines, ranging from regulation and financing of medicines, intellectually property rights protection, and development of innovation capacity, to other health system components. Multiple policies have been implementing in China to remove the multiple access barriers gradually. Universal access to medicines has been moving from towards the basic common conditions to the world breakthrough technologies. We see cause for optimism, but recognize that there is a long way to go. Achieving broader and better access to modern medicines for Chinese patients will require multiple and coordinated government efforts, which would need to target the whole lifecycle regulation of novel medicines with a health system perspective, from balancing IP protection, strengthening $R \& D$ and public health, to appropriate regulatory approach and financing mechanism, and to supply chain management, as well as smart use.
\end{abstract}

Keywords: access to novel medicines, regulatory, affordability, IP, R\&D, health system

\section{Summary}

Many studies reviewed access to essential medicines in China, little is known about access to novel medicines, barriers of access, as well as how these barriers have been resolved progressively. Looking at access to new therapies from a health system perspective, and placing the changes China has made in the past 10 years into that system context, this paper makes a comprehensive review of access to novel medicines in China.

\section{Introduction}

The human right of access to health and medicines is one of the fundamental human being rights well founded in international law. ${ }^{1}$ China's 2009 healthcare reform responded to this international concept, aiming to provide affordable and equitable basic healthcare for all by 2020. Access to medicines is an essential part of access to basic healthcare. Equitable access to medicines that match the needs of basic 
healthcare has been gradually achieved during the past ten years. Driven by the rising healthcare awareness and needs fueled by the country's economic growth and burgeoning middle-class, demands for new therapies are rendering a blowout in China. To meet such growing demands, there must be a faster access to market of the new therapies that goes hand in hand with access for a broader population.

However, as of 2015, over half of the world's most important novel medicines launched after 2008 as measured by global sales were not yet approved in China. Most were breakthrough treatments, representing a new standard of care with a significant impact on life saving and patient outcomes. ${ }^{2}$ In addition, the high cost of new life-saving therapies creates a significant barrier to patients in low- and middle-income countries with the latest advances in care treatment. ${ }^{3}$ As there is still quite a large number of poor population living in middle-income countries $^{4}$ - this raises a lot of challenges because originator pharmaceutical companies set the price of a medicines like commercial product by what the market will bear, and they view the middle-income countries as a market that can bear the cost. ${ }^{5}$ While China has been very successful in raising millions out of poverty, the size of its population means that huge numbers are still in the low-income group - this makes equitable access a big challenge. The situation has been so acute in China that travel agencies have popped up to offer medical tourism services to the rich looking for medications overseas. There are also an increasing number of patients seeking non-registered cheap medicines from overseas market. ${ }^{6}$ Voices of patients reached to the top policy makers. Furthermore, there are growing challenges with funding new medicines at ever-increasing prices along with funding increased medicines volumes with the growth of demand. This has resulted in the reforms to better manage the entry of new medicines, development of new financial models to finance new medicines as well as strategies to improve supplying and prescribing efficiency. Looking at access to new therapies from a health system perspective, and placing the changes China has made in the past 10 years into that system context, this paper makes a comprehensive review of access to novel medicines in China.

\section{Methods}

This study used content analysis methodology to review the existing literature and the information obtained from the key informant interview. We searched English and Chinese database of PubMed, Embase, Google Scholar,
China National Knowledge Infrastructure, Wangfang, and VIP. Search terms included "access/accessibility", "novel/ new/innovative/breakthrough", "medicines/drug/pharmaceutical/therapy/medication", "China/Chinese", and combinations of these terms in both English and Chinese. The PubMed search strategy and the keywords in Chinese were presented in Annexure 1. The publishing dates were 2000-2019. Duplicated articles, clinical trials, clinical or laboratory medicines evaluations were excluded. A review of references in key papers, news sources, government statistical handbooks were also performed. A substantial body of evidence available in grey literature was identified as well, including landmark or highly regarded reports, work suggested by peers and government documents.

The study also drew on insights into the key informants from relevant government agencies, about their understanding of the access problems and government efforts to address these problems. R\&D-based multinational and local pharmaceutical companies, as well as independent market research institutions were also interviewed, focusing on their experiences of facing the access barriers and in-depth thinking of the reform initiatives. Detailed information about the key informant interview was described in Annexure 2.

\section{Key Findings And Discussions Lifecycle Regulation Of Pharmaceuticals}

As presented in Figure 1, patient access to new pharmaceutical products has to go through the following process in China. Pharmaceutical companies or research institutes initiate the preliminary inception of a new product. Extensive pre-clinical and clinical research activities followed through, during which research and development (R\&D) capacity and regulatory system play a critical role to determine successful discovery of new molecules, development of new products, and timely launch. Intellectual property (IP) policy environment impacts market monopoly and generic competition.

Like in many other countries, listing of products by the government as essential medicines is usually a prelude to being covered by public funds in China, which is always synchronized with government price negotiations. Listings by the provincial pooled procurement management agency and individual hospital formulary are also the essential steps for patient access. After being successfully procured by hospitals, medicines are distributed by either wholesalers or manufacturers to hospitals. Doctors and 


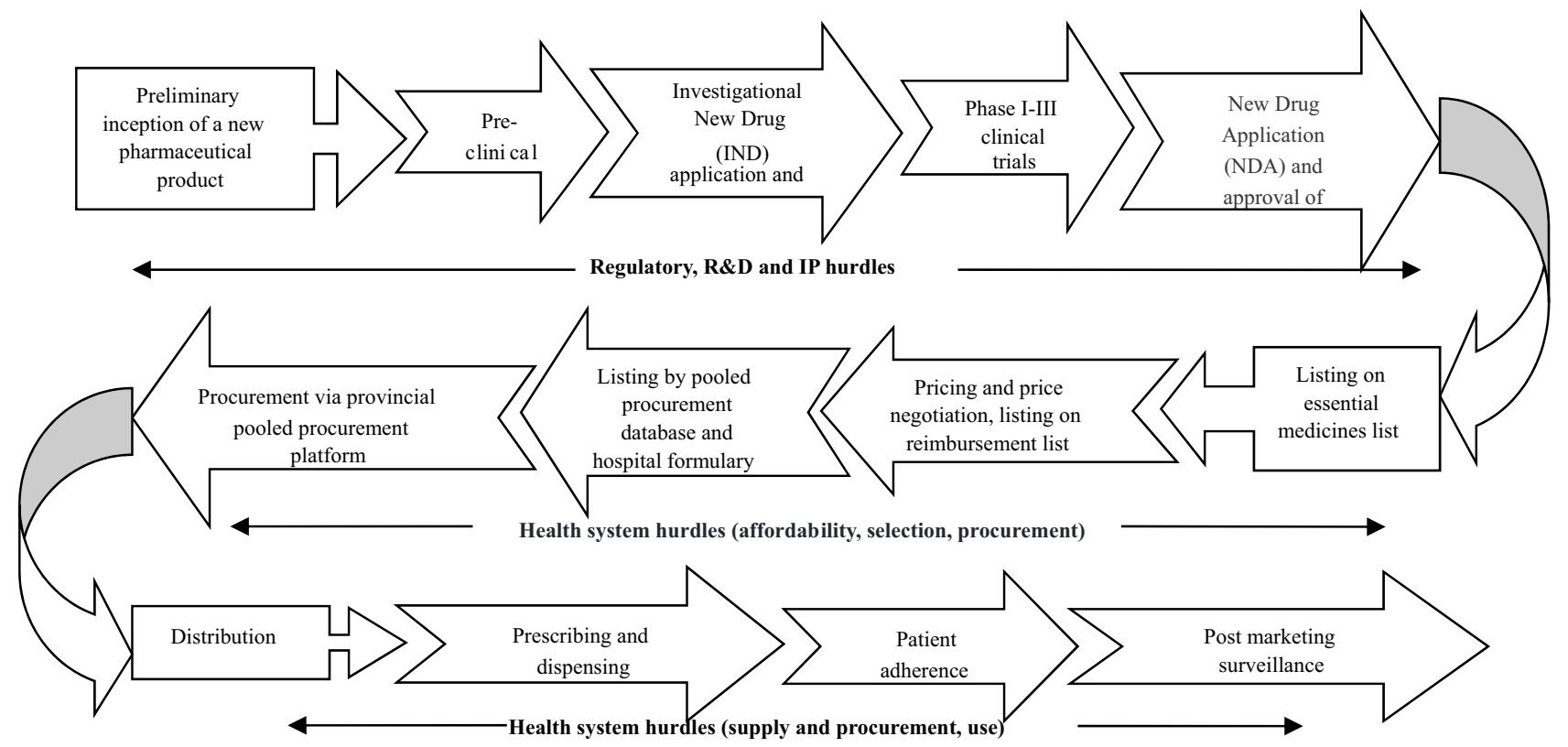

Figure I Lifecycle regulation of new pharmaceutical products in China.

pharmacists can then prescribe and dispense. Patient utilization, tolerance and adherence are monitored by both health professionals and pharmaceutical companies thereafter. Both health insurance programs and health administrative authorities play important roles in having the new products financially and physically available to appropriate patients.

\section{Hurdles Of Access To Novel Medicines Regulatory Hurdle}

Before 2015, new medicines already launched in the Western world typically experienced five to seven years of delays before being launched in China. The average review time for approval of clinical trials (Investigational New Drug, IND) was 8-18 months in China, followed by another 4-15 months in average for review and evaluation of a new drug application (NDA). IND application in the United States (US) and the European Union (EU) only takes 1-2 months. The total length of approval time for IND and NDA in China vs US vs EU was $12-33,7-17$ and 11-17 months, respectively. ${ }^{7-9}$ One reason for such a significant delay is the limited human resource of the Chinese national regulatory authority (NRA), which is severe shortage of drug evaluators. Only about 100 reviewers received an overwhelming number of clinical trials and marketing applications for both novel medicines and redundant generics. ${ }^{10}$ The number of annual new applications was between 6500 and 7000 during
2009-2012, only part of the applications could be processed, and the number of backlogged applications reached its peak at 22,000 in mid-2015..$^{11,12}$

In addition, before 2017, new medicines to be registered in China must undergo clinical trials locally, even though the medicines were already marketed in other countries. This is unique and not required in most other countries. Domestic trials could be exempted if previous trials included large groups of Asian patients, which has been difficult to achieve historically. Such complex process and conservative attitude of NRA toward clinical trials of novel medicines substantially exacerbated the approval delays. The regulatory barriers have discouraged the marketing of innovative programs in China by eroding larger revenues from patent protection.

\section{IP Hurdle}

Evidence proves that high prices of branded originator medicines and no legal production of generics increase the catastrophic costs - as well as morbidity-mortality of medication in lower income countries. ${ }^{13}$ Generic competition is associated with lower medicines prices. $^{14,15}$ However, some life-saving medicines have been highly priced before patent expiration even in the settings where there is a capacity of producing cheaper generics. The problem has arisen in many developing countries where the population not only have lower economic status, but also lower health status and higher needs for medicines. 
The case of generic imatinib in China demonstrated several potential barriers of IP protection to effective generic competition for specialty prescription medicines, including fewer market entrants, smaller-than-expected price reductions, shifts in prescribing toward more expensive brandname treatments, and limited uptake of the generic products. $^{16}$ Even though several Chinese companies already had the capacity to develop generics, importation of the high-priced originator had to continue, due significantly to patent protection granted to foreign manufacturers. ${ }^{17}$ The IP barrier also blocked access to affordable antiretrovirals in several developing countries. In South Africa, where giant pharmaceutical companies filed lawsuits to the High Court against the South African government because of importation of cheaper generics during the HIV/AIDS epidemic. Millions of people were suffering from HIV/AIDS and could not afford the original branded medicines. ${ }^{18}$

\section{R\&D Hurdle}

Although China had seen significant growth in pharmaceutical production over the preceding decade, a substantial proportion of the nearly 5000 local pharmaceutical manufacturers was generic producers. Limited R\&D input and tolerance to uneven quality of local generics exacerbated the prevalence of low-end generic producers, and aggravated the low investment and fragmentation of small-scale local pharmaceutical companies. ${ }^{19,20}$ Accord ing to the National Bureau of Statistics, the input of R\&D by Chinese high-tech pharmaceutical industry never exceeded $1.7 \%$ of its major sales before 2017 (National Bureau of Statistics of China 2019), which was far below that of the international R\&D-based pharmaceutical industry, $17.1 \%$ in US, $13.3 \%$ in Japan, and $13.3 \%$ in EU. $^{21}$ Government investment has for a long time been injected into public research institutions and universities, but few of their basic research results were converted to commercial products. $^{22}$ The transformation rate of science and technology in pharmaceutical R\&D in China (10$30 \%$ ) was far below that of the developed countries (4070\%). ${ }^{23-25}$ Another important gap is the talent bottleneck. The talent pool of R\&D management rather than basic research has been an important limiting factor in China's growth as a pharma innovator. ${ }^{26}$

\section{Other Health System Hurdles}

Even if the local R\&D capacity is developed, the needed medicines are available on the market, patients may still not be able to physically and financially access the medicines. Patient needs risk pooling mechanisms to avoid catastrophic medicines expenditure. And new medicines need to be added to the hospital formulary, and go through the complex procurement procedures.

\section{Financial Risk Pooling Mechanism}

Once on the market, new medicines are often too expensive for most patients to initiate treatment, or to comply with desired treatments to achieve health outcomes in China. Taking cancer treatment as an example, China relies heavily on importation. Many of the imported novel medicines are priced for the markets of high-income countries, and are not publicly funded in China, presenting a huge burden to families. A study in Zhejiang province found that, before being funded by the local health insurance program, patients had to pay out-of-pocket 3.0-13.1 and 6.2-27.3 times of the provincial average disposable annual income per capita in urban and rural areas, respectively, for novel anti-cancer medicines in $2015 .^{27}$ Affordability blocked the access to dozens of life-saving novel medicines in China, which was veritably reflected by "Dying to survive," a dark comedy about Chinese leukemia patients buying cheaper anti-cancer medicines from the Indian market. The film triggered intense public debates about access to affordable healthcare and novel medicines across the country. ${ }^{28}$ However, the public enthusiasm for these medicines' therapeutic value is tempered by practical concerns on how health systems can afford them, as even in high-income countries the affordability is a growing concern. ${ }^{29}$

\section{Financing Of Public Hospitals}

As public hospitals are not allowed to mark-up on medicines in China now, the increasing costs of pharmacy management and inventory control discouraged hospitals to procure expensive novel medicines. Apart from this, hospitals also have concerns of over running the insurance expenditure cap, and have been fettered by the administrative rules regarding medicines expenditure control. ${ }^{30}$ The worst scenario was that some hospitals turned down patients to avoid exceeding the expenditure cap. ${ }^{31}$ These medicines may be available in some retail pharmacies, however, few insurance programs reimburse medicines dispensed in retail pharmacies.

\section{Supply Chain Management}

In the rural areas, the weak health service delivery system 
and health human resources, as well as the limited capacity of last-kilometer supply and distribution may also block patients' physical access to novel medicines. As these medicines are mostly specialty prescription medicines, many of them are targeted therapies, which need genetic testing and careful monitoring to guide the personalized medication. All these need well-trained specialists and laboratory assistants to deliver. However, these resources are always not available in the resource-limited contexts, especially in remote poor rural areas. Such situation is common in the developing countries where there are generally weak health systems, especially in rural areas.

\section{Efforts To Overcome Multiple Hurdles}

Over the past years, the access environment of China has been moving from a system driven primarily by out-ofpocket payment to one offering a myriad of access opportunities. This is due to the changing philosophy of the government, and its responding to WHO's call for listing highly effective breakthrough novel medicines as essential medicines and making them affordable for the patients. ${ }^{32}$ The experiences of developing countries like Thailand and Brazil who already explored such approaches were studied and regarded as examples to follow. ${ }^{33,34}$ The environment has been shifting from limited to increased access, but only for therapies that demonstrate appropriate clinical value. Positive developments have taken place intensively in the entire lifecycle regulation of pharmaceuticals. ${ }^{35}$

\section{Streamlining New Medicines Evaluation And Creating An Efficient Process}

The entry point of the regulatory reforms started from the mandated self-examination and inspection of clinical trial data in 2015, which successfully cracked down on data fraud and ensured data authenticity and integrity. Backlog pressure was also relieved. Subsequent comprehensive reforms have been targeting improving efficiency and creating a responsive review and regulatory process. Major critical reforms have been under the direct leadership of the State Council, who has been clearly committed to resolve the backlog, and to accelerate the time-to-market of novel medicines. Milestones and landmark policies to streamline the regulatory process are presented in Figure 2.

With the implementation of intensive regulatory reforms, the backlog of applications was nearly cleared by the end of $2018 .^{36}$ International pharmaceutical companies have responded to the trend and accelerated the pace of "global synchronization". The length of time for launching new products by multinational pharmaceutical companies has been greatly shortened, and Chinese patients are expected to benefit from such "global synchronization". During 2014-2016, there were only 7 new products approved through the priority review process, this number reached to 50 in 2017 and 83 in 2018 . The average length of time for the 1st round of evaluation of IND, NDA and Abbreviated New Drug Application (ANDA) was 39, 59 and 81 working days, respectively, in 2017, $90 \%$ new applications for registration were processed according to the timeline as defined by the State Council drug regulatory reform opinion in 2018, and the number of backlogged applications dropped from 22,000 to 3440 by the end of 2018. The clinical trials of 170 novel products were approved in 2017, which almost doubled the number in $2016 .{ }^{36,37}$ Considering that the reforms may have undesired effects, for example, fast-track approvals based on limited evidence may lead to products on the market that lack effectiveness for the general population, these approvals are conditional. Companies are required to provide post-marketing clinical data to corroborate safety and efficacy of the fast-track approved novel medicines.

In 2017, China became the eighth regulatory member of the International Council for Harmonization of Technical Requirements for Pharmaceuticals for Human Use (ICH), pledged to gradually transform its pharmaceutical regulatory authorities, industry and research institutions to implement the international coalition's technical standards and guidelines. Full understanding and swift implementation of $\mathrm{ICH}$ are considered as the best way to set the foundation for medicines innovation and patient access to high-quality medicines in China.

\section{Balancing The IP Protection And Public Health Security}

China formulated its National IP Strategy and clearly committed to build a high level of protection of innovation and application by 2020. To address the IP barrier, the national Patent Law and regulations were revised to incorporate some flexibilities in the legal provisions for public health needs. There has been a clear government commitment to balance the IP protection and generic competition, which was written in the recent national policy for promotion of generic uptakes and local R\&D capacities strengthening. ${ }^{38}$ However, these flexibilities have yet to be implemented in reality in China like in Thailand, India and Malaysia, who used their rights under the 


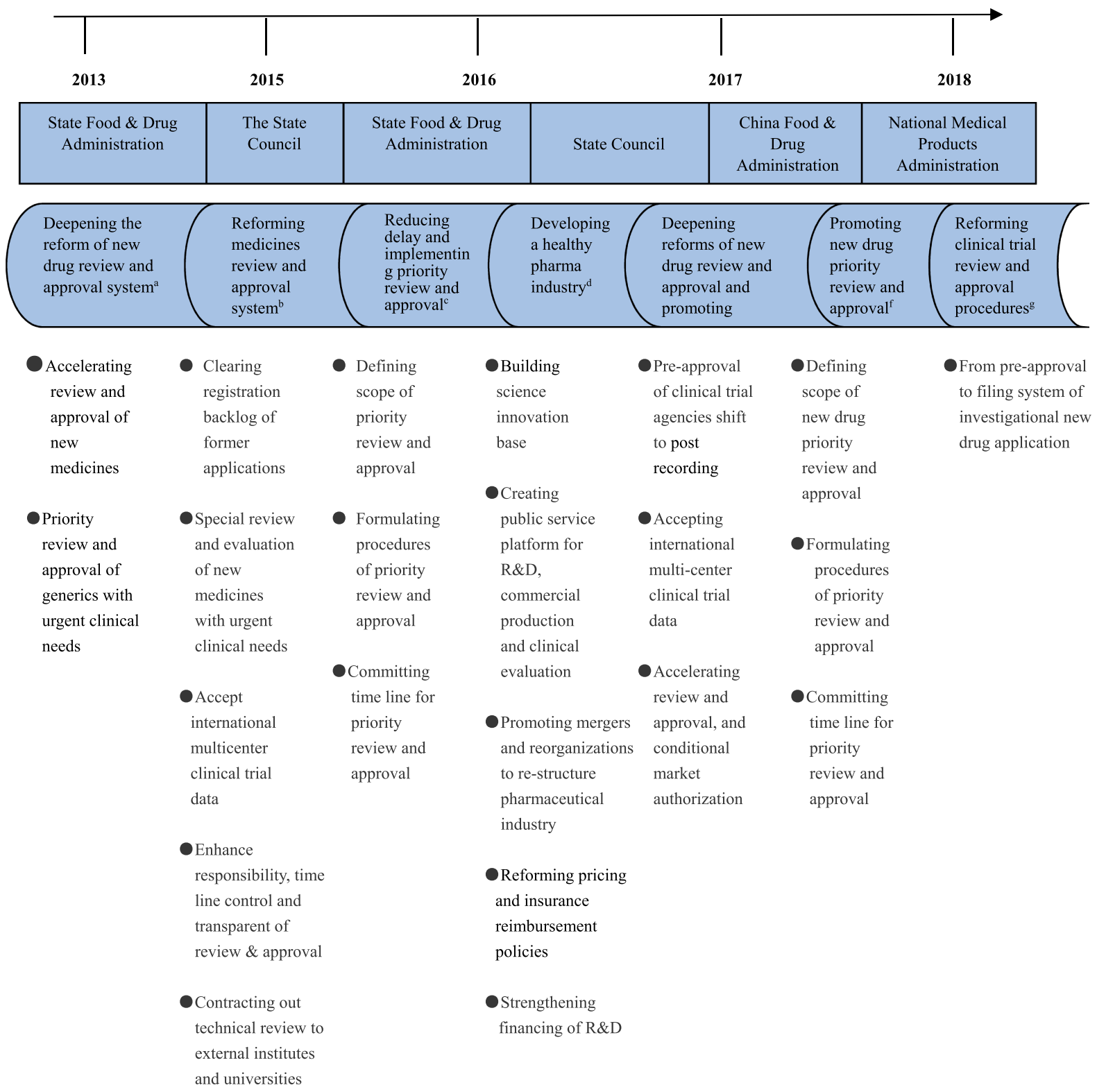

Figure 2 Milestones and landmark policies to streamline the regulatory process.

Notes: ${ }^{a}$ National Medical Products Administration. Deepening thel National Medical Products Administration. Deepening the reform of review and approval system and promoting medicines innovation. Document No. 37 of 2013. http://www.nmpa.gov.cn/WS04/CL2196/323982.html (in Chinese, accessed July 30, 2019). ${ }^{b}$ The State Council. Opinions of reforming review and approval systems of medicines and medical devices. Document No. 44 of 20I5. http://www.gov.cn/zhengce/content/20I5-08/I8/content_ 10101.htm (in Chinese, accessed July 30, 2019). ${ }^{\circ}$ China Food and Drug Administration. Reducing delay of medicines registration and implementing priority review and approval. Document No. 19 of 2016 (Abolished and replaced by a new document issued in reform of review and approval system and promoting medicines innovation. Document No. 37 of 2013. http://www.nmpa.gov.cn/WS04/CL2196/323982.html (in Chinese, accessed July 30, 2019). ${ }^{d}$ The State Council. Opinions of reforming review and approval systems of medicines and medical devices. Document No. 44 of 2015. http://www.gov.cn/zhengce/content/2015-08/I8/content_10I0I.htm (in Chinese, accessed July 30, 2019). ${ }^{\mathrm{e}} \mathrm{China}$ Food and Drug Administration. Reducing delay of medicines registration and implementing priority review and approval. Document No. 19 of 2016 (Abolished and replaced by a new document issued in 2017). http://samr.cfda.gov.cn/WSOI/CL0844/I45260.html (in Chinese, accessed July 30, 2019). ${ }^{\mathrm{f}}$ The State Council. Promoting healthy development of the pharmaceutical industry. Document No. II of 20I6. http://www.gov.cn/zhengce/content/20I6-03/II/content_5052267.htm (in Chinese, accessed July 30, 2019). ${ }^{8}$ Chinese Communist Party Central Committee and State Council. Opinions to deepening the reform of review and approval system and promoting medicines and medical devices innovation. http://www.gov.cn/zhengce/2017-I0/08/content_5230I05.htm (in Chinese, accessed July 30, 20I9). ${ }^{\mathrm{h}} \mathrm{National}$ Medical Products Administration. Promoting new drug priority review and approval. Document No. 126 of 2017. http://www.nmpa.gov.cn/WS04/CL2I96/324/93.html (in Chinese, accessed July 30, 2019). 'National Medical Products Administration. Reforming clinical trial review and approval procedures. Announcement No.50 of 20I8. http:// www.nmpa.gov.cn/WS04/CL21 II/3297/6.html (in Chinese, accessed July 30, 2019).

flexibilities contained in the Trade-related Intellectual Property Rights Agreement (TRIPS) administered by the World Trade Organization. ${ }^{39,40}$ The use of compulsory licenses by developing governments can be seen since 2003, mostly for antiretrovirals for HIV/AIDs, and most recently for sofosbuvir for hepatitis $\mathrm{C}$ treatment in 
Malaysia in $2017 .{ }^{41}$ The guiding role of intellectual property in economic and public policies needs to be strengthened. More efforts need to be adopted to improve coordination between intellectual property policy and the policies of industry, science and technology and trade. Coordination and uniformity between intellectual property policy and policies of science and health need to be strengthened to safeguard the right of the public to legally and rationally utilize innovation findings and information in their scientific and public health activities, promote the fair sharing of innovation and information, prevent abuses of intellectual property, maintain fair market competition, safeguard the public lawful rights properly and interests and ensure that the government is able to deal with public crises.

\section{National Strategy Of Fostering Innovation-based Pharmaceutical Industry}

Same as another world power of generics producer, China adopted a similar national strategy like India to foster pharmaceutical innovation. This happened in China five years after its entering into WTO, with the National Middle-to-Long Term Science \& Technology Development Plan (2006-2020), which identified pharmaceutical R\&D as one of the national major bio-technology projects, and aimed to build a national pharmaceutical R\&D system, foster a bio-pharmaceutical strategic emerging industry, and shift the pharmaceutical industry from generics focus towards innovation based. While India did this in 2002 as soon as its Patent Law was amended compelled by the government's commitment under the TRIPS Agreement. Creating an environment for R\&D to produce innovator drugs was regarded as one of the key objectives of both Chinese and Indian National Pharmaceutical Policies. ${ }^{42}$ The market size of the biopharmaceutical industry has been maintaining a rapid growth accompanied with accelerating technological achievements since the National Plan was implemented in China. In 2012, China laid out a national strategy to adjust and upgrade its industrial structure, and strived to be a world technological power by 2049. A series of supportive policies to encourage $R \& D$ and commercialization of pharmaceuticals with minimal market barriers have been formulated, such as the marketing authorization holder (MAH) pilot which allowed R\&D institutions and scientific research personnel to submit applications for INDs or NDAs; a science-based regulatory system in line with the international technical standards; IP system that rewards innovation through patent protection; talent building; scientific research base and robust capital market, etc. In addition, preferential fiscal and taxation policies were formulated to promote the development of R\&D-based pharmaceutical industry. The value-added tax (VAT) on medicines is $17 \%$, which is higher than the level of $10 \%$ in most EU countries with UK and Sweden even implementing a zero VAT rate on prescription medicines. In 2018, all imported anti-cancer medicines were exempted from tariffs and all local business of anti-cancer medicines were levied with a lower VAT at $3 \% .^{43,44}$ This policy was expanded to orphan drugs since February 2019. ${ }^{45}$

Investment in pharmaceutical R\&D increased significantly in China, especially in the area of translational medicine, a partnership between basic and clinical research to develop new pharmaceuticals and other medical products. At present, the main body of pharmaceutical R\&D has been transforming from public research institutes and universities to the joint efforts with pharmaceutical companies, either state owned or private biomedical technology companies. The central government has invested CNY 15.5 billion (about US\$ 2.3 billion) in new medicines major development projects during 2008-2018. Up until end of 2018, 35 novel medicines have been locally developed and marketed. ${ }^{46}$ The number of locally developed new molecular entities has grown rapidly, with clinical trials on these increased from 21 in 2011 to 171 in 2017, and further increased to 198 in 2018. ${ }^{11,36,47}$ An accelerating shift in China's R\&D landscape is already leading to increased $R \& D$ capabilities of the local pharmaceutical industry. China has therefore been emerging as a major innovation hot spot. However, comparing with the US federal spending on medical and health R\&D in 2017 (US\$34 billion, about $0.2 \%$ of gross domestic product, GDP), public spending on pharmaceutical R\&D in China only accounted for $0.02 \%$ of its GDP. ${ }^{48,49}$ In addition, the gap between Chinese and multinational pharmaceutical companies is also huge, there is only on average $1.02 \%$ of the sales invested in R\&D by Chinese companies, few is higher than $5 \%$, while that for the multinationals is generally over $15 \%{ }^{50}$

\section{Strengthening And Integrating Health Systems \\ Reimbursement Of Novel Medicines For Critical Diseases} Medicines price setting reform in 2015 was the first initiative to address the affordability issue. Medicines pricing has been gradually shifting from government setting to market-orientation, accompanied with provider payment 
reforms. During 2016-2018, three rounds of medicines price negotiations at central level had the prices of 56 expensive novel medicines almost halved, and included in the medicines reimbursement list of the basic health insurance programs. ${ }^{51-53}$ Local health insurance programs also piloted medicines price negotiations and had additional novel medicines publicly funded. ${ }^{54}$ The newly established National Healthcare Security Administration (NHSA) committed to make the price negotiation and public fund coverage of novel medicines routinely from 2019 onwards. ${ }^{55}$ This reflects the government's efforts to provide coverage for therapies that offer proved value for the healthcare system and improve overall health of the population, even though these medicines are usually expensive. However, as the insurance coverage of these novel medicines was designed with a high deductible payment for individuals before insurance reimbursement, the desired and potential undesired effects are to be assessed with sound quasi-experimental and mixed method studies, especially for the low-income population in rural areas. In this regard, Thailand's universal coverage of the E2 expensive essential medicines is worthwhile for China to learn from, in order to secure that every needed patient can benefit from the novel medicines coverage inclusion policy. $^{33}$

Although China achieved universal coverage of the basic health insurance program, the scope of medicines coverage is far less than adequate, and special needs are usually not covered. The Chinese government is also concerned with its ability to sustain the social welfare system due to its rapidly aging population. There has been an effort to boost investment in the private healthcare insurance which has been rapidly growing: the average growth rate of the commercial healthcare insurance market is approximately $25 \%$ since 2000 , changing from a very small proportion of the total health expenditure $(0.4 \%$ in 1997) to a level $(8 \% \text { in } 2017)^{56}$ which was close to the level of the high to upper middle-income countries, like the Republic of Korea (9.5\%), Australia (7.8\%), New Zealand (7.2\%) and Indonesia $(6.1 \%) .{ }^{57,58}$ The continued growth of commercial insurance will broaden overall coverage and may supplement public coverage for expensive therapies.

\section{Appropriate Financial Incentives To Promote Smart Use}

To ensure the supply and rational use of the newly publicly funded novel medicines, a series of policies were formulated. Health insurance programs set separate budgets for expensive novel medicines, and the "one-size-fits-all" evaluation indicator of "medicines expenditures should be less than $30 \%$ of total expenditure" was abolished, in order to alleviate hospitals' worries of over-running the insurance expenditure cap. ${ }^{59}$ Instead, insurance programs require hospitals to carefully monitor the use of expensive novel medicines, and value-based cost-effectiveness evaluation is being implemented to promote competition between hospitals to rationally use resources. Considering that expanded medicines coverage will certainly require more resources, and the overall per capita healthcare resources are still limited in China, efforts have been made to discourage the use of medicines with unclear clinical efficacy and encourage the uptake of generics with secured quality and clinical efficacy. This will make rooms for novel medicines that offer proven clinical value. In 2018, the newly established NHSA piloted a pooled medicines procurement in 11 major cities of China. Prices of 25 medicines which have both originator and generics (quality and clinical efficacy verified) on the market were reduced by $52 \%$ on average. ${ }^{60}$

\section{Conclusion}

Multiple policies have been implementing in China to remove the multiple access barriers gradually. Universal access to medicines has been moving from towards the basic common conditions to the world breakthrough technologies. We see cause for optimism, but recognize that there is a long way to go. Achieving broader and better access to modern medicines for Chinese patients will require multiple and coordinated government efforts, which would need to target the whole lifecycle regulation of novel medicines with a health system perspective, from balancing IP protection, strengthening $R \& D$ and public health, to appropriate regulatory approach and financing mechanism, and to supply chain management, as well as smart use.

\section{Abbreviations}

$\mathrm{R} \& \mathrm{D}$, research and development; IP, intellectual property; IND, investigational new drug; NDA, new drug application; US, United States; EU, European Union; NRA, national regulatory authority; OECD, Organization for Economic Cooperation and Development; ANDA, abbreviated new drug application; ICH, Harmonization of Technical Requirements for Pharmaceuticals for Human Use; NHSA, National Healthcare Security Administration; TRIPS, Trade-related Intellectual Property Rights Agreement; 
MAH, marketing authorization holder; VAT, value-added tax; GDP, gross domestic product.

\section{Acknowledgment}

The authors appreciate all the interviewees who provided support to and shared their insights with the study team.

\section{Disclosure}

The authors declare that they have no competing interests in this work.

\section{References}

1. Hogerzeil $\mathrm{H}$, Access to essential medicines as a human right. World Health Organisation. Essent Drugs Monit. 2003;33:25-26. Available from: http://apps.who.int/medicinedocs/en/d/Js4941e/5.html. Accessed July $3,2019$.

2. Deu FL. How Patient Do Chinese Patients Need to Be. McKinsey \& Company Greater China. Published on March 31, 2016. Available from: https://www.linkedin.com/pulse/how-patient-do-chinesepatients-need-franck-le-deu. Accessed September 27, $2019 .$.

3. Farmer P, Frenk J, Knaul FM, et al. Expansion of cancer care and control in countries of low and middle income: a call to action. The Lancet. 2010;376(9747):1186-1193. doi:10.1016/S0140-6736(10) 61152-X

4. Sumner A Where will the world's poor live. CGD Working Paper 305. Washington, D.C.: Center for Global Development. Available from: http://www.cgdev.org/content/publications/detail/ 1426481. Accessed October 8, 2019.

5. Drabu S, Khatri S, Singh S, et al. Drugs and money - prices, affordability and cost containment. Int J Pharm Healthc Mark. 2011;5(1):67-69. doi:10.1108/17506121111121596

6. China Daily USA. China Society. Cancer patients look to India for lifesaving drugs. 2015 January 28. Available from: http://usa.chinada ily.com.cn/china/2015-01/28/content_19426279.htm. Accessed July 3, 2019.

7. Deloitte. Fortune favors the bold unlocking access across China. Available from: https://www2.deloitte.com/content/dam/Deloitte/cn/ Documents/life-sciences-health-care/deloitte-cn-lshc-chinalshcindus tryreportsection4-en-081014.pdf. Accessed July 3, 2019.

8. Downing NS, Aminawung JA, Shah ND, et al. Regulatory review of novel therapeutics - comparison of three regulatory agencies. $N$ Engl J Med. 2012;366:2284-2293. doi:10.1056/NEJMsa1200223

9. Regulatory Affairs Professional Society, Pharma Asia. China proposes new FDA rules to speed up foreign drug approvals. 2017 March 20. Available from: https://www.fiercepharma.com/pharmaasia/china-officially-process-to-speed-up-foreign-drug-approval. Accessed July 3, 2019.

10. Center for Drug Evaluation, National Medical Products Administration, About us. Development history. Available from: http://www.cde.org.cn/htmlPage.jsp?htmlPageId=4. (in Chinese) Accessed October 7, 2019.

11. Center for Drug Evaluation, National Medical Products Administration. Annual report of China drug review 2012. Available from: http://www.cde.org.cn/news.do? method= largeInfo\&id=312956. (in Chinese). Accessed July 3, 2019.

12. Xu L, Gao H, Kaitin KI, et al. Reforming China's drug regulatory system. Nat Rev Drug Discov. 2018;17:858-859. doi:10.1038/ $\operatorname{nrd} .2018 .150$

13. Ahmadiani S, Nikfar S. Challenges of access to medicine and the responsibility of pharmaceutical companies: a legal perspective. DARU. 2016;24:13. doi:10.1186/s40199-016-0151-z
14. United States Government Accountability Office. Drug pricing: research on savings from generic drug use. Available from: https:// www.gao.gov/assets/590/588064.pdf. Accessed July 3, 2019.

15. Hill A, Simmons B, Gotham D, et al. Rapid reductions in prices for generic sofosbuvir and daclatasvir to treat hepatitis C. $J$ Virus Eradication. 2016;2(1):28-31. PMID: 27482432. PMC4946692.

16. Cole AL, Dusetzina SB. Generic price competition for specialty drugs: too little, too late? Health Aff. 2018;37(5):738-742. PMID: 29733710. doi:10.1377/hlthaff.2017.1684

17. Sun J, Zhao H, Ma L, et al. Affordability of expensive medicines with significant public health implications under the intellectual property right protection system. Chinese J Evidence Based Med. 2014;14(5):509-516. (in Chinese). doi:10.7507/1672-2531.20140088

18. Ncayiyana D. Antiretroviral therapy cannot be South Africa's first priority. CMAJ. 2001;164(13):1857-1858.

19. Luo W, Sun L, Zhou J.Evaluation of pharmaceutical industry structure optimization in China. Chinese J New Drugs. 2016;25(14):15661571. (in Chinese).

20. Meng X, Song Y. SWOT analysis of generics development in China. China Pharm. 2016;27(28):3889-3892. (in Chinese). doi:10.6039/j. issn.1001-0408.2016.28.01

21. European Commission. Economics of industrial research and innovation. The 2015 EU Industrial R\&D Investment Scoreboard. Available from: https://iri.jrc.ec.europa.eu/rd_monitoring. Accessed November 22, 2019.

22. Sun Y, Sun LH.Empirical analysis on the effect of pharmaceutical scientific \& technological investment from government on pharmaceutical R\&D expenditure. China Pharm. 2011;22(9):771-774. (in Chinese).

23. Yang Z, Yuan J, Yin M. Present status analysis on domestic medicine technological innovation products incubators. Soft Sci Health. 2016;30(6):48-50. (in Chinese). doi:10.3969/j.issn.1003-2800.2016. 06.012

24. Li ZJ, Ma Y, Liu Y, et al. Descriptive systematic review on collaborative innovation of health industry in China. Chin Health Serv Manage. 2017;34(6):477-480. (in Chinese).

25. Wu L, Chen Y. Novel drug research and development ability in China: an international comparison and analysis. Chinese $J$ Health Policy. 2017;10(08):23-28. (in Chinese). doi:10.3969/j.issn.16742982.2017.08.005

26. Deloitte. Opportunity and influence for localized development pharmaceutical R\&D trends in China. Available from: https://www2. deloitte.com/cn/en/pages/life-sciences-and-healthcare/articles/pharma ceutical-rd-trends-in-china.html. Accessed July 3, 2019.

27. Diao Y, Qian J, Liu Y, et al. Government insurance coverage and use and affordability of expensive targeted anti-cancer medicines in China: an interrupted time-series study. The Lancet. 2018;392 (Supplement 1):S37. doi:10.1016/S0140-6736(18)32666-7

28. Lucas C. Dying to survive and cancer care in China. Lancet Oncol. 2019;20(1):30. doi:10.1016/S1470-2045(18)30921-5

29. Perehudoff K, Toebes B, Hogerzeil H. A human rights-based approach to the reimbursement of expensive medicines. Bull World Health Organ. 2016;94(12):935-936. doi:10.2471/BLT.15.166371

30. Science and Technology Daily News. How to address procurement barrier of novel medicines after evaluation process has been speed up? 2018 October 17. Available from: http://www.medsci.cn/article/ show_article.do?id=1b40151303a1. (in Chinese). Accessed July 3, 2019.

31. People's Daily. Why hospital buck passing patients? 2012 December 06. Available from: http://cpc.people.com.cn/pinglun/n/2012/1206/ c78779-19809787.html. (in Chinese). Accessed November 22, 2019

32. National Health Commission. Policy interpretation of the 2018 national essential medicines list. 2018 October 25. Available from: h t t p : / / www.nhc.gov.cn/yaozs/s $3582 / 201810 /$ de12303b26a046e49d725f375fb31315.shtml. (in Chinese). Accessed October 7, 2019 
33. Sun J, Jiang F, Zhao Q, et al. The successful experiences of a developing country in achieving universal access to expensive lifesaving medicines and it implications to China. China Pharm. 2017;28 (3):289-294. (in Chinese). doi:10.6039/j.issn.1001-0408.2017. 03.01

34. Fonseca EM, Shadlen K, Bastos F. Brazil's fight against hepatitis C - universalism, local production, and patents. $N$ Engl J Med. 2019;380:605-607. doi:10.1056/NEJMp1812959

35. Jiang Y, Bi K. A view on compare of international new drugs innovation system with enlightenments to China. Sci Manage S.\& T. 2010;31 (2):40-45. (in Chinese). doi:10.1016/S1570-6672(09)60061-1

36. Center for Drug Evaluation. National Medical Products Administration. Annual Report of China Drug Review 2018. Available from: http://www.nmpa.gov.cn/WS04/CL2196/338621. html. (in Chinese). Accessed July 3, 2019.

37. Shao R, Zhao D, Jiang R.Policies and trends of innovative drug research and development in China. China Food Drug Adm Magazine. 2018;16(01):15-19. (in Chinese).

38. United Nations Development Programme Asia-Pacific regional centre. Intellectual Property Rights and Access to Affordable ARVs in China. Bangkok: UNDP; 2013.

39. Chee YL, Chen X. Intellectual property right and accessibility of inexpensive medicines: lessons from Asian countries. Pat Law Res. 2007.

40. Kaplana WA, Ritzb LS, Vitelloc M, et al. Policies to promote use of generic medicines in low and middle income countries: a review of published literature, 2000-2010. Health Policy. 2012;106(3):211-24.

41. Khor M Compulsory license and "Government Use" to promote access to medicines: some examples. Third World Network: Malaysia; 2014. Available from: http://www.twn.my/title2/books/ CompulsoryLicense.htm. Accessed July 3, 2019.

42. Department of Pharmaceuticals of India. Pharmaceutical Policy 2002. 2002 February 15. Available from: http://pharmaceuticals.gov.in/pol icy/pharmaceutical-policy-2002. Accessed July 3, 2019.

43. Ministry of Finance. Notice on VAT policy of anti-cancer drugs. Documents No. 47 of 2018. Available from: http://www.chinatax.gov. $\mathrm{cn} / \mathrm{n} 810341 / \mathrm{n} 810755 / \mathrm{c} 3421680 /$ content.html. (in Chinese). Accessed July 3, 2019.

44. Statista. Health \& Pharmaceuticals. Pharmaceutical Products \& Market. VAT rate on prescription-only drugs in Europe 2018. Available from: https:/www.statista.com/statistics/458957/vat-rateon-prescription-only-drugs-in-europe/. (in Chinese). Accessed July 3, 2019.

45. State Taxation Administration. VAT policy for rare disease drugs. Document No. 24 of 2019. Available from: http://www.chinatax.gov. $\mathrm{cn} / \mathrm{n} 810341 / \mathrm{n} 810755 / \mathrm{c} 4082485 /$ content.html. (in Chinese). Accessed July 3, 2019.

46. Sang G. Progress of the 2018 national major new medicines developments project and forecast of the 13th five-year plan. China Biotechnol. 2019;39(2):3-12. (in Chinese). doi:10.13523/j.cb.201 90202

47. Chai H, Liu Z, Wang Z. Preliminary analysis on the establishment of drug innovation system and the innovation progress of Chinese pharmaceutical enterprises. West China Med J. 2018;33(03):359363. in Chinese. doi:10.7507/1002-0179.201801164
48. National Bureau of Statistics of China. public spending on pharmaceutical R\&D. Available from: http://data.stats.gov.cn. (in Chinese). Accessed July 3, 2019.

49. Congressional Budget Office of the United States. Estimating the long-term effects of federal R\&D spending: CBO's current approach and research needs. 2018 June 21. Available from: https://www.cbo. gov/publication/54089. Accessed July 3, 2019.

50. Chu Y, Ma A. R\&D expenditure analysis of Chinese pharmaceutical companies. Mod Bus Trade Ind. 2013; 2: 3-5. Available from: https:// www.china-briefing.com/news/chinas-commercial-healthcare-insur ance-industry-on-the-fast-track/. (in Chinese). Accessed July 31, 2019

51. National Health Commission. The announcement of the results of medicines price national negotiation. Document No. 515 of 2016. 2016 May 20. Available from: http://www.nhc.gov.cn/yaozs/s7655/ 201605/58c5bc1ed0f14c75b8f15f1c149b35f4.shtml. (in Chinese). Accessed October 8, 2019.

52. Ministry of Human Resources and Social Security. The announcement of inclusion of 36 national price negotiation medicines into the basic health insurance medicines reimbursement list. Document No. 54 of 2017. 2017 July 13. Available from: http://www.mohrss.gov.cn/ SYrlzyhshbzb/shehuibaozhang/zcwj/201707/t20170718_274153. html. (in Chinese). Accessed October 8, 2019.

53. National Healthcare Security Administration. Notice on the inclusion of 17 anti-cancer medicines into the national basic health insurance medicines reimbursement list. Document No.17 of 2018. 2018 October 10. Available from: http://www.nhsa.gov.cn/art/2018/10/10/ art_37_1057.html. (in Chinese). Accessed October 8, 2019.

54. Li C, Cui D, Peng H, et al. Practical study of brining negotiation medicines into health insurance management. Chinese J Hosp Manage. 2018;38(5):39-41. (in Chinese).

55. National Healthcare Security Administration. Workplan for the adjustment of the national basic health insurance medicines reimbursement list 2019. Available from: http://www.nhsa.gov.cn/art/2019/4/ 17/art_37_1214.html. (in Chinese). Accessed September 30, 2019.

56. China National Health and Development and research center of the national health commission of P.R. China. China health account report. Beijing: CNHDRC;2018. (in Chinese).

57. Dezan Shira \& Associates. China Briefing. China's Commercial Healthcare Insurance Industry on the fast-track. 2015 December 24. Available from: https://www.china-briefing.com/news/chinas-com mercial-healthcare-insurance-industry-on-the-fast-track/. Accessed July 31, 2019.

58. Sekhri N, Savedoff W. Private health insurance: implications for developing countries. Bull World Health Organ. 2005;83(2):127138. doi:10.1590/S0042-96862005000200013

59. General Office of the State Council of the People's Republic of China. Strengthening the Performance Appraisal of Third-level Public Hospitals. (2019) 4. http://www.gov.cn/zhengce/content/ 2019-01/30/content_5362266.htm. (in Chinese) Accessed November $22,2019$.

60. People's Daily. Prices of selected drugs in 11 pilot cities dropped by 52\% on average. Available from: http://www.gov.cn/zhengce/201901/18/content_5358881.htm. (in Chinese). Accessed July 3, 2019. 


\section{Publish your work in this journal}

Risk Management and Healthcare Policy is an international, peerreviewed, open access journal focusing on all aspects of public health, policy, and preventative measures to promote good health and improve morbidity and mortality in the population. The journal welcomes submitted papers covering original research, basic science, clinical \& epidemiological studies, reviews and evaluations, guidelines, expert opinion and commentary, case reports and extended reports. The manuscript management system is completely online and includes a very quick and fair peer-review system, which is all easy to use. Visit http://www.dovepress.com/testimonials.php to read real quotes from published authors.

Submit your manuscript here: https://www.dovepress.com/risk-management-and-healthcare-policy-journal 